\title{
Evolution, Achievements, and Challenges for New Cooperative Medical Schemes in Rural China
}

\author{
Kun Zhu*, Xiaojuan Zhang, Shasha Yuan, Miaomiao Tian \\ Institute of medical information, Chinese Academy of Medical Sciences \& Peking Union Medical College, Beijing, China \\ Email:*zhukun@imicams.ac.cn
}

How to cite this paper: Zhu, K., Zhang, X.J., Yuan, S.S. and Tian, M.M. (2016) Evolution, Achievements, and Challenges for New Cooperative Medical Schemes in Rural China. Modern Economy, 7, 1564-1583. http://dx.doi.org/10.4236/me.2016.713140

Received: October 8, 2016

Accepted: November 28, 2016

Published: December 1, 2016

Copyright $\odot 2016$ by authors and Scientific Research Publishing Inc. This work is licensed under the Creative Commons Attribution International License (CC BY 4.0).

http://creativecommons.org/licenses/by/4.0/

\begin{abstract}
Objectives: To describe the development of NCMS in the past decade including three sections and to bring up relevant policy implications. Methods: Based on secondary data and literature review, the evolution and achievement of NCMS in the past decade and the expected future challenges were analyzed. Results: Impressive advances have been seen in establishing the largest medical insurance system, New Cooperative Medical Scheme (NCMS), covered more than 800 million farmers in rural China during the past decade. Remarkable achievements during the development of NCMS include universal health coverage among rural residents, rapid increasing premium, balanced pooling fund, improved service, cost and coverage of farmers, and a strengthened primary health care system. In the meantime, the NCMS also confronted certain challenges: Institutionalization and legalization lagged behind the development of NCMS; payment reform failed to control the rapid growth of medical expenditure and financial protection for enrollees was insufficient; solidarity and equity between NCMS and other medical insurance systems is still an issue that needs to be solved; sustainable financing mechanism was not established successfully and moreover, it was also not compatible with the aging population and epidemiological transition of rural China; double coverage for rural residents turned up as portability was not achieved.
\end{abstract}

\section{Keywords}

New Cooperative Medical Scheme, Rural China, Health Financing, Primary Health Care, Universal Health Coverage

\section{Introduction}

Establishment of health financial protection for rural residents in China has experienced ups and downs since the foundation of People's Republic of China (P.R.C.) in 1949 [1]. 
The first recorded Cooperative Medical Scheme (CMS) was instituted in Mishan Town, Gaoping county, Shanxi Province in 1955. The CMS was primarily financed by the welfare fund of the communes (collective farming) [2] [3]. It organized health stations, paid village doctors to deliver primary care, and provided prescription drugs. From the 1950s to the 1970s, CMS was an integrated part of the overall collective system for agriculture production and social services in China. In the late 1970s, the peak of CMS movement, CMS covered $90 \%$ of all villages and provided widespread financial mechanisms for farmers to access basic health services in rural China [2].

In the late 1970s, CMS, together with barefoot doctors (village doctors) and rural threetiered health delivery networks, successfully gave rural residents access to primary health care [4] [5]. However, with the transition from the collective system to the Household Responsibility System in 1979, the communes disappeared. Without its funding base, the CMS collapsed, leaving around 90\% of all farmers uninsured [6] [7] [8].

During the late 1980s and early 1990s, there was an attempt to re-establish CMS. These early insurance schemes typically pooled money from the whole population $(10,000-50,000)$ of a township [9]. The number of the schemes grew slowly, and they varied a great deal [10]. However, most of these attempts were difficult to sustain for a long time, especially in poor rural areas because of inadequate funding, dwindling political interest and poor management. Very few of these schemes survived into the new millennium [11] [12].

In 1993, risk-pooling mechanisms (the government, state enterprise insurance systems and rural community financing schemes) covered only $21 \%$ of the population [13] and only $9.81 \%$ of rural residents were covered by CMS [14]. Moreover, this rate kept declining from 1993 to 1998 , and only $6.57 \%$ of rural residents remained covered by CMS in 1998 [15].

Consequently, the majority of rural residents had to pay their medical expenditure out of pocket (OOP). Around one third of rural residents could not receive timely access to primary health care due to lack of health insurance coverage. Health care expenses led 2.5\% of households to fall below the poverty line in 1995, [16] and 22\% of poor households attributed their poverty to illness or injury in 1998 [15]. Under this context, illness became a leading contribution to poverty in rural areas [17] [18]. In addition, equity of health financing also worsened as rural residents had to seek more frequent care with OOP. In 2000, equity of health financing in China ranked $4^{\text {th }}$ last in the world by World Health Organization (WHO) [19].

Increasing medical demands among rural residents coupled with the high cost of medical services severely decreased access to health care for rural residents [20]. How to build a health financing system for rural residents and make them equitable and affordable access to primary health care became one of the priorities for policymakers in China [21].

To address these problems, the China National Rural Health Conference was held in Beijing in October 2002. The Central Committee of the Communist Party of China (CPC) and the State Council released a "Decision on Further Strengthening Rural 
Health Care Work", the first document on rural health issues from the Central Committee since the foundation of the P.R.C. [22]. It clearly documented the creation of a new medical insurance system for rural residents, the New Cooperative Medical Scheme (NCMS). It required different levels of governments establish NCMS step by step and cover nearly all rural residents by the end of 2010 [22]. In 2003, the Ministry of Health (MOH), Ministry of Finance (MOF), and Ministry of Agriculture (MOA) jointly issued directives on the establishment of NCMS [23].

NCMS has made impressive progress in the past ten years since CPC Central Committee and State Council declared this new medical insurance system for rural residents. Covering more than 800 million rural residents, NCMS has become the largest social medical insurance scheme in the world and has won international recognitions for its success [24] [25].

This paper aims to describe the development of NCMS in the past decade including three sections: the evolution of NCMS, the achievement of NCMS in rural China, and the challenges on NCMS development. Finally, relevant policy implications are proposed to shed some light on the developing countries with the same goal to achieve universal health coverage.

\section{Methodologies}

\subsection{Data Collection Methods}

\subsubsection{Secondary Data}

Most data on NCMS was collected from the Bureau of Rural Health Management within the $\mathrm{MOH}$. National operating data on NCMS was collected from the national handbook of new rural cooperative medical scheme information and China health statistical yearbooks from 2004 to 2014. Data on co-payment rates for NCMS enrollees was collected from the national health financial statement yearbook between 2004 and 2013 and the reports of National Health Service Survey in 1993, 1998, 2003, 2008. Data about access to primary care was also collected from the reports of National Health Service Survey in 1993, 1998, 2003, 2008. Some data on access and reimbursement was collected from a mid-review report on China's health reform progress, which was the result of a National Health Service survey conducted in 2011. Process-tracing was used and all the national documents on NCMS from 2002 to 2013were collected and reviewed.

\subsubsection{Literature Review}

Our review was based on both international and domestic reports, official documents, and published papers. We searched Pub Med, Google Scholar, the Social Science Research Network, and China Knowledge Resource Integrated Database for articles and publications since 2003; we also included cross-references, landmark or highly regarded reports, and work suggested by peer reviewers. The language was limited to English and Chinese by using the search terms, "health insurance", "medical insurance", "cooperative medical scheme", "cooperative medical system", "rural health financing", "financial risk protection", "universal health coverage", "health security", "equity”, "healthcare 
reform", "health reform", and "China", and combinations of these terms. The date of the last search was Dec 31, 2013.

\subsection{Analysis Framework}

In accordance with the aim of this paper, the entire contents are developed around the evolution and achievement of NCMS in the past decade and the expected future challenges. The evolution was divided into three periods, the piloting period (2002-2006), the scaling up period (2007-2008) and the fixing and development period (2009present). The four greatest achievements of NCMS include; a pooling fund including premium collection, payment and balance; population, service and cost coverage based on the universal health coverage framework proposed by WHO in 2010 [26]; a delivery system with emphasis on primary health care; and advancement of portability. The following main challenges of NCMS were identified, institutionalization and legalization of NCMS, deepening solidarity and financial protection, creating a more sustainable financing mechanism, cost containment and the future portability of NCMS.

\section{Results}

\subsection{Evolution of NCMS}

\subsubsection{Piloting Period (2002-2006)}

In October, 2002, "Decision to further strengthen health work in rural areas", issued by CPC Central Committee and the State Council, required that government establish NCMS in rural areas in order to protect rural residents from poverty due to catastrophic disease [22]. This policy was regarded as the birth of NCMS. In 2003, "Directives on the Establishment of New Rural Cooperative Medical System" was issued by $\mathrm{MOH}$, MOF, and MOA, which symbolized the beginning of NCMS in rural China [23].

During the initial stage in 2003, 257 counties from 29 provinces were selected as piloting sites [27]. NCMS covered 31 provinces in China in 2004 and the number of piloting counties increased rapidly to 333, 678, 1451 in 2004, 2005 and 2006 respectively [28] [29] [30].

\subsubsection{Scaling up Period (2007-2008)}

After three years' pilot, rural residents had a better understanding of NCMS and were gradually more likely to participate. Based on the successful piloting experience, $\mathrm{MOH}$ decided to expand NCMS to all rural residents within the country. In January 2006, $\mathrm{MOH}$, together with National Development and Reform Commission (NDRC), MOF, MOA, State Food and Drug Administration (SFDA), and SATCM, issued a notice on the advancement of NCMS. It required local governments push the expansion of NCMS forward and clearly documented that $40 \%$ and $60 \%$ of counties should be covered by 2006 and 2007 respectively, and all counties need to be covered by NCMS by 2008 [31]. Simultaneously, public finance should play a more important role in the financing of NCMS. In 2007, a national conference on NCMS was held in Xi'an city, capital of Shaanxi province, and a speech by Vice Prime Minister Wu Yi, demanded the scaling up of NCMS throughout the entire country [32]. As a result, NCMS rapidly 
expanded, and all counties (2729) were covered by NCMS in rural China by 2008 [33] [34].

\subsubsection{Fixing and Developing Period (2009-Present)}

In July 2009, based on "Opinions of the CPC Central Committee and the State Council on Deepening the Health Care System Reform" [35] issued in April 2009, MOH, together with Ministry of Civil Affair, MOF, MOA and SATCM, issued an opinion on fixing and developing NCMS [36] which symbolized NCMS entering in to a new period.

During this period, the focus of NCMS changed from population coverage to payment reform for providers, containment of growing medical expenditures, lower copayment rate and reduction of disease burden incurred by rural residents. Figure 1 shows the changing trends in the number of counties and the coverage rate covered by NCMS from 2003 to 2013.

\subsection{Achievements}

\subsubsection{Pooling Fund}

Premiums increased rapidly and the pooling fund remained steadily balanced. CMS experienced ups and downs several times before 2003 [37] [38], therefore nobody could forecast how rural residents would respond to NCMS [35]. Initially, "30 Yuan"1 premium was collected in pilot counties, with equal contributions by central government, local government and rural residents [39]. The collected premium was divided into two parts: unified pooling fund (inpatient fund) and household medical saving accounts (outpatient fund). Most premiums were allocated to inpatient funds because inpatient service was seen as priority coverage for NCMS. Unified pooling fund occupied $87.60 \%$ and $88.27 \%$ of premiums in 2006 and 2007 respectively [30] [33]. Some counties in developed areas increased the premium at the beginning so that it could benefit more to

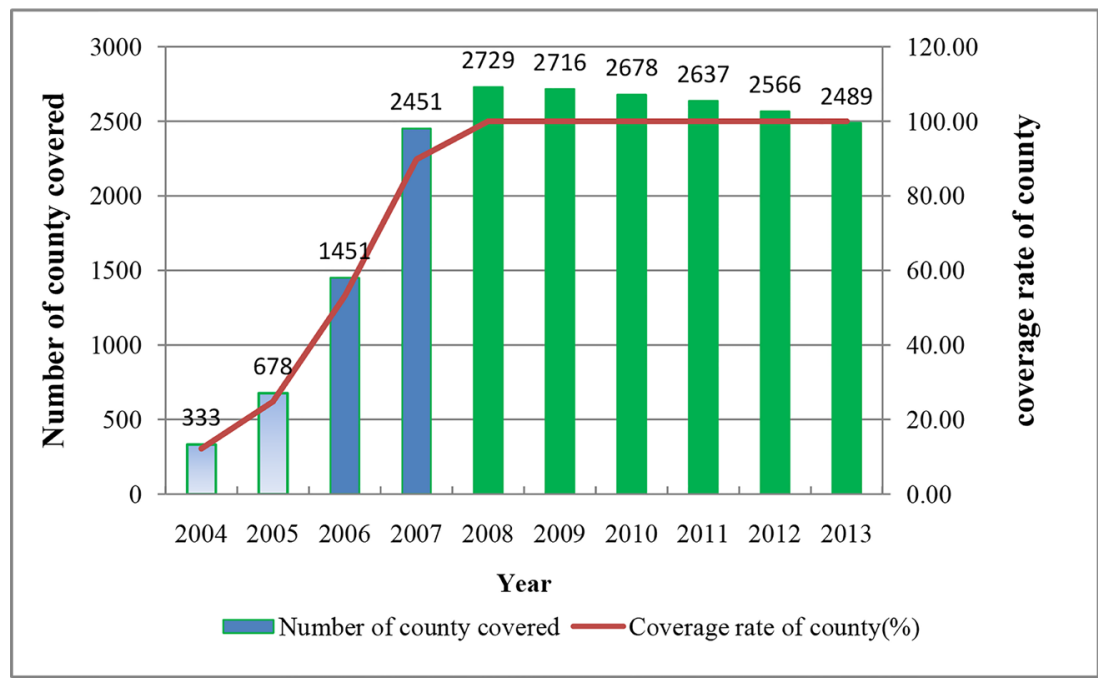

Figure 1. County with NCMS coverage from 2004 to 2013 in China.

${ }^{1}$ According to exchange rate from Bank of China, 1 amounts to 8.28 and 6.10 RMB in Dec. $31^{\text {st }}, 2003$ and Dec. $31^{\text {st }}, 2013$ respectively. 
the insured [40]. Some rural residents remained suspicious of NCMS and were not willing to be covered by this new scheme even when premiums were low [41]. As shown in Table 1 and Figure 2, in 2003-2004, premiums were $¥ 44.32$ on average across China, and individual contributions accounted for about one third. In 2005, premiums were $¥ 42.14$, and individual contribution accounted for $38.13 \%$. After 2005 , premiums increased gradually from $¥ 52.11$ in 2006 to $¥ 245.17$ in 2011 . Public finance from central and local government (including province, prefecture and county) played an increasingly important role in NCMS financing. Individual's share of premiums decreased from $27.16 \%$ in 2006 to $14.79 \%$ in 2011 . Premium as percentage of net income for rural residents increased from $1.44 \%$ in 2005 to $4.14 \%$ in 2011 , and individual contribution as percentage of net income for rural residents decreased from $0.55 \%$ in 2005 to $0.36 \%$ in 2008, and then gradually increased to $0.75 \%$ in 2013.The fund of NCMS remained steadily balanced, and premium always remained higher than payment from 2003 to 2013.

\subsubsection{Population Coverage}

With the stable development of NCMS, farmers were inclined to enroll because they realized it was different from CMS. In 2004, 84.04 million farmers were covered by NCMS, and the coverage rate of the poor was $75.2 \%$ and $71.51 \%$. Since then, NCMS rapidly expanded coverage. In 2011, 831.63 million farmers, 97.50\% of rural residents in China, were covered by NCMS (Figure 3). After eight years of pilot and development, it has become the largest medical insurance scheme around the world. NCMS, together with a basic medical insurance system for urban employees and urban residents, covered more than $95 \%$ of the total population, which makes China one of the countries approaching universal health coverage.

Table 1. Payment and premium of NCMS and its share as net income for rural residents in China between 2003 and 2013.

\begin{tabular}{ccccc}
\hline Year & $\begin{array}{c}\text { Premium } \\
\text { per capita } ¥)\end{array}$ & $\begin{array}{c}\text { Payment } \\
\text { per capita } ¥)\end{array}$ & $\begin{array}{c}\text { Premium as \% of net } \\
\text { income for rural residents }\end{array}$ & $\begin{array}{c}\text { Individual contribution as \% } \\
\text { of net income for rural residents }\end{array}$ \\
\hline $2003-2004$ & 44.32 & 32.8 & - & - \\
2005 & 42.14 & 34.54 & 1.44 & 0.55 \\
2006 & 52.11 & 38.01 & 1.60 & 0.43 \\
2007 & 58.93 & 47.73 & 1.64 & 0.37 \\
2008 & 95.94 & 81.25 & 2.32 & 0.36 \\
2009 & 113.02 & 110.78 & 2.37 & 0.49 \\
2010 & 156.14 & 142.15 & 3.03 & 0.57 \\
2011 & 245.17 & 205.64 & 4.14 & 0.61 \\
2012 & 308.54 & 299.01 & 3.90 & 0.70 \\
2013 & 370.59 & 362.58 & 4.17 & 0.75 \\
\hline
\end{tabular}

Data source: National handbook of NCMS information from 2004 to 2013. 


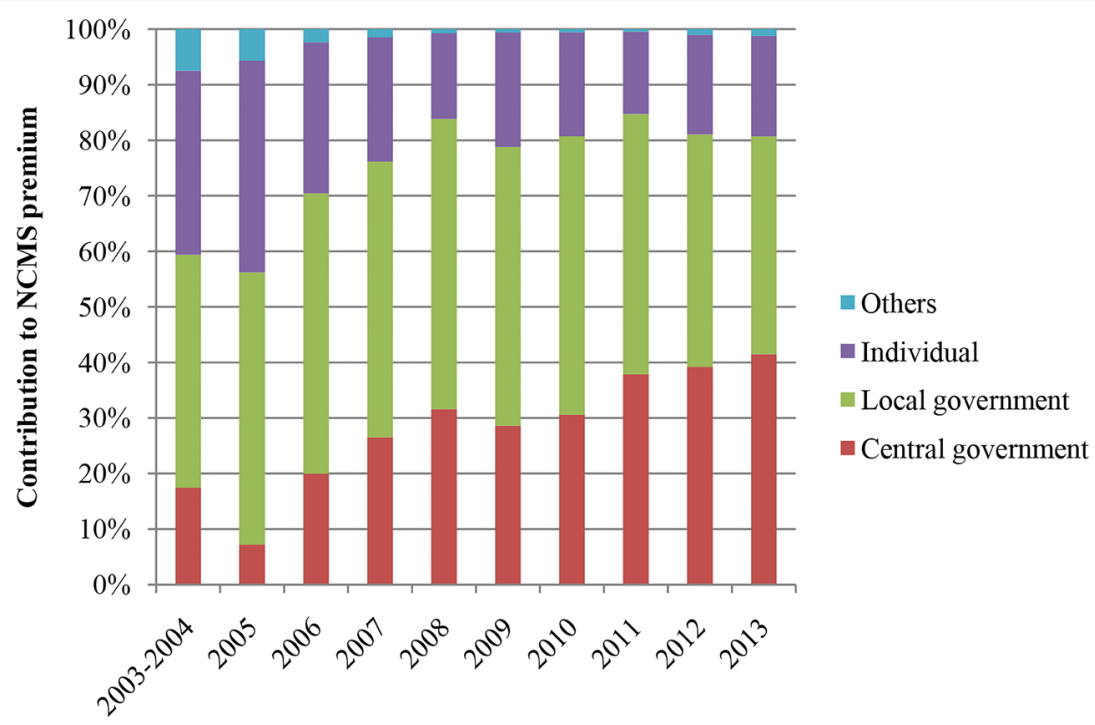

Figure 2. Contribution to NCMS premium in China between 2003 and 2013; Data source: National handbook of NCMS information between 2004 and 2013.

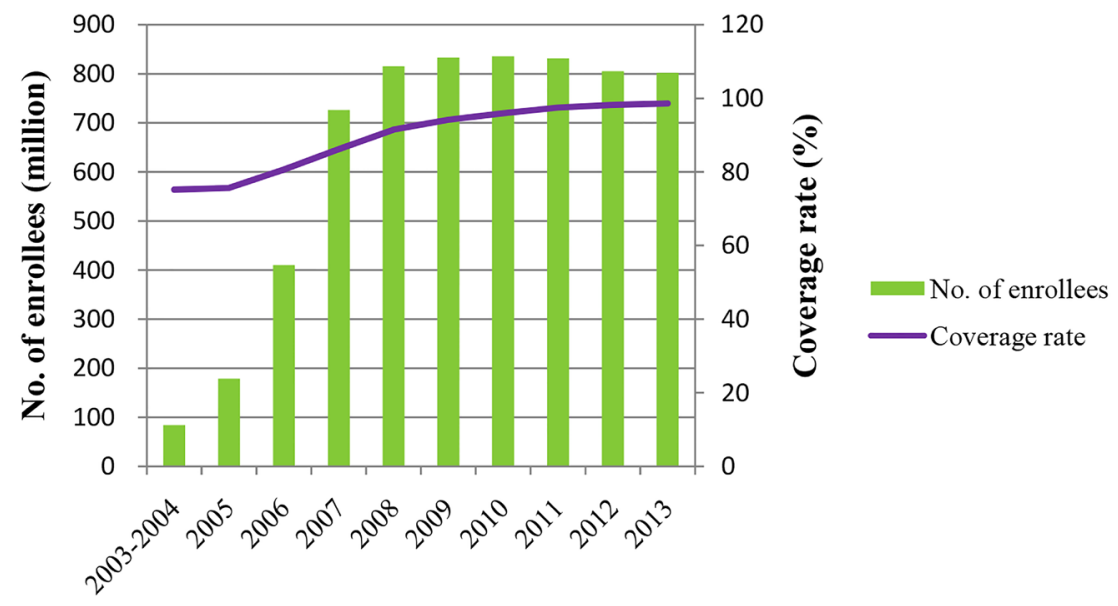

Figure 3. NCMS coverage in China from 2003 to 2013; Data source: National handbook of NCMS information from 2004 to 2014.

\subsubsection{Service Coverage}

Benefit package became more inclusive. At the beginning of NCMS, the benefit package was very limited. Inpatient and delivery services were seen as priorities, while outpatient service and physical examination were only included in some counties [40]. The benefit package remained unchanged while premiums remained low from 2003 to 2007. Outpatient expenditures for catastrophic diseases were included into the benefit package in many counties due to increasing premiums in 2008 [42]. In June, 2010, inpatient expenses for specific catastrophic diseases, such as congenital health diseases and leukemia in children, were also included into the NCMS benefit package due to a declaration on improving medical security for major childhood diseases in rural China issued by $\mathrm{MOH}$ and Ministry of Civil Affair [43]. In September 2010, nine medical rehabilitation 
services and items were included into the benefit package of NCMS when including medical rehabilitation services into benefit packages of basic medical securities was required by $\mathrm{MOH}$, Ministry of Human Resource and Social Security, Ministry of Civil Affair, MOF, and China Disabled Person's Federation [44].

With an increasingly wider benefit package, rural residents received easier access to primary care. Some evidences showed an increase in the utilization of preventive services and outpatient and inpatient service for rural residents [45] [46] [47]. As shown in Table 2, visit rates within two weeks for rural residents increased from $13.9 \%$ in 2003 to $15.3 \%$ in 2011 , and then declined to $12.8 \%$ in 2013 , which was higher than urban areas during the same term [48]. Admission rates for rural residents increased from $3.4 \%$ in 2003 to $6.8 \%$ in 2008 , and reached $9.0 \%$ in 2013 [48] [49] [50]. The gap of admission rates between urban and rural areas changed between 2003-2013. Self-discharge rates for rural residents decreased from $47.0 \%$ in 2003 to $16.7 \%$ in 2013, and the gap between urban and rural residents reduced gradually [48] [49] [51]. Inpatient delivery increased significantly in rural China between 2003 and 2011. As shown in Figure 4, only 62.0\% of pregnant women in rural China delivered their babies in hospitals in 2003, lagging significantly behind urban China (92.6\%). But changes have taken place and in 2011, 95.9\% of pregnant women in rural China selected delivery in hospitals, slightly higher than urban China (95.5\%) [48].

Delivery service was included into the benefit package during the initiation of NCMS in 2003, which made most pregnant women deliver in hospitals [52] [53]. As a direct result, neonatal and maternal mortality rate in rural areas decreased. In 2003, the neonatal mortality rate in rural China was $20.1 \%$ and $8.9 \%$ in urban areas (Figure 4) [54]. As NCMS expanded, the neonatal mortality rate in rural areas decreased more than urban areas and the gap between urban and rural areas was reduced. Similar trends were seen in the maternal mortality rate between 2003 and 2013 in rural and urban areas in China. In 2013, the maternal mortality rate in rural China was 23.6 per 100,000, nearly the same as urban areas $(22.4$ per 100,000$)$ [55]. CMS was considered to narrow the gap of life expectancy between urban and rural residents in 1980s; 13 and the development of NCMS implied it could narrow the gap of health status in neonatal \& maternal mortality between urban and rural residents [56] [57].

Table 2. Access to medical services for urban and rural residents in China.

\begin{tabular}{ccccccc}
\hline \multirow{2}{*}{ Year } & \multicolumn{2}{c}{ Visit rate within Two weeks (\%) } & \multicolumn{2}{c}{ Admission rate (\%) } & \multicolumn{2}{c}{ Self-discharge rate (\%) } \\
\cline { 2 - 7 } & Rural residents & $\begin{array}{c}\text { Urban } \\
\text { residents }\end{array}$ & Rural residents & $\begin{array}{c}\text { Urban } \\
\text { residents }\end{array}$ & Rural residents & $\begin{array}{c}\text { Urban } \\
\text { residents }\end{array}$ \\
\hline 2003 & 13.9 & 11.8 & 3.4 & 4.2 & 47.0 & 34.5 \\
2008 & 15.2 & 12.7 & 6.8 & 7.1 & 39.3 & 29.6 \\
2011 & 15.3 & 13.7 & 8.4 & 10.1 & 33.7 & 27.2 \\
2013 & 13.3 & 12.8 & 9.0 & 9.1 & 16.7 & 17.6 \\
\hline
\end{tabular}

Data source: Report of the 3rd and 4thnational health service survey in 2003, 2008 and mid review report on China's health reform progress in 2011. 


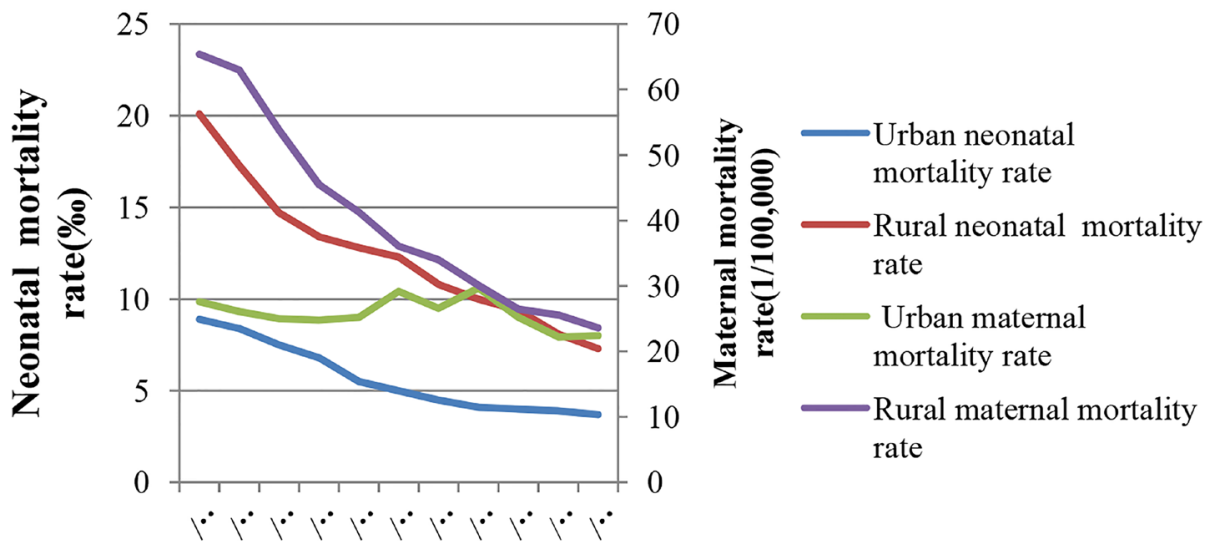

Figure 4. Neonatal and maternal mortality rate from 2003 to 2013 in China; Data source: National health statistics yearbook from 2004 to 2014.

\subsubsection{Cost Coverage}

Co-payment rate for medical expenditure decreased. With increasing financing and a wider benefit package, farmer's co-payment rate for inpatient expenditure decreased from $74.28 \%$ in 2004 to $43.4 \%$ in 2013. But co-payment rate for outpatient expenditure fluctuated in the past decade, it was $69.35 \%$ in 2004 , then reached the summit of $82.11 \%$ in 2007, and decreased to $48.1 \%$ in 2013 gradually (Figure 5). A National Health Service Survey in 2011 also showed reimbursement rates of inpatient expenditure reached $50.5 \%$ when NCMS enrollees used hospitalization services, but reimbursement rate for outpatient expenditure was only 23.2\% [58]. Some evidences before 2009 also showed that NCMS has not led to a reduction in out-of-pocket spending, which sometimes even increased, and hypothesize that copayments reduction have been off-set by increased service use [45] [59] [60].

\subsection{Portability}

With rapid economic development in China, many farmers left their hometown and found jobs in urban areas. NCMS adopted household based enrollment, which meant portability would have a deep impact on farmers' equitable access to timely medical services [61]. Rural patients could not receive reimbursement on point when discharged from hospitals outside their registration county due to lack of or insufficient information network between NCMS offices and designated hospitals during the first two stages [62]. During the third stage, focus on portability was an important issue. In order to solve farmers' on point reimbursement when they used health service out of their registration county, an information network was set up between NCMS county offices and contract hospitals. By the end of December 2011, rural patients could receive on point reimbursement in $81.5 \%$ counties when they used health service in their registration provinces. A national NCMS platform began in 2011 so rural residents could receive on point reimbursement when they used health services out of provinces [57]. 


\section{Delivery System of Primary Care}

Primary health care system was strengthened. At the beginning of the 21 st century, China's rural three-tiered health care network declined due to low investment from public finance, and some township hospitals confronted the dilemma of collapse [63]. In the first stage in NCMS, township hospitals were in the process of declining but improvements occurred when NCMS covered more than 50\% of counties in China by 2006. The rural residents covered by NCMS used outpatient and inpatient services in township hospitals more frequently because they now received a high reimbursement from NCMS fund (Figure 6). Therefore, China's primary health care system was consolidated and strengthened and became more prosperous and vigorous as NCMS expanded after 2006 [64]. Some studies confirmed that NCMS increased the intensity of inpatient care at township health centers and outpatient care at both village clinics and

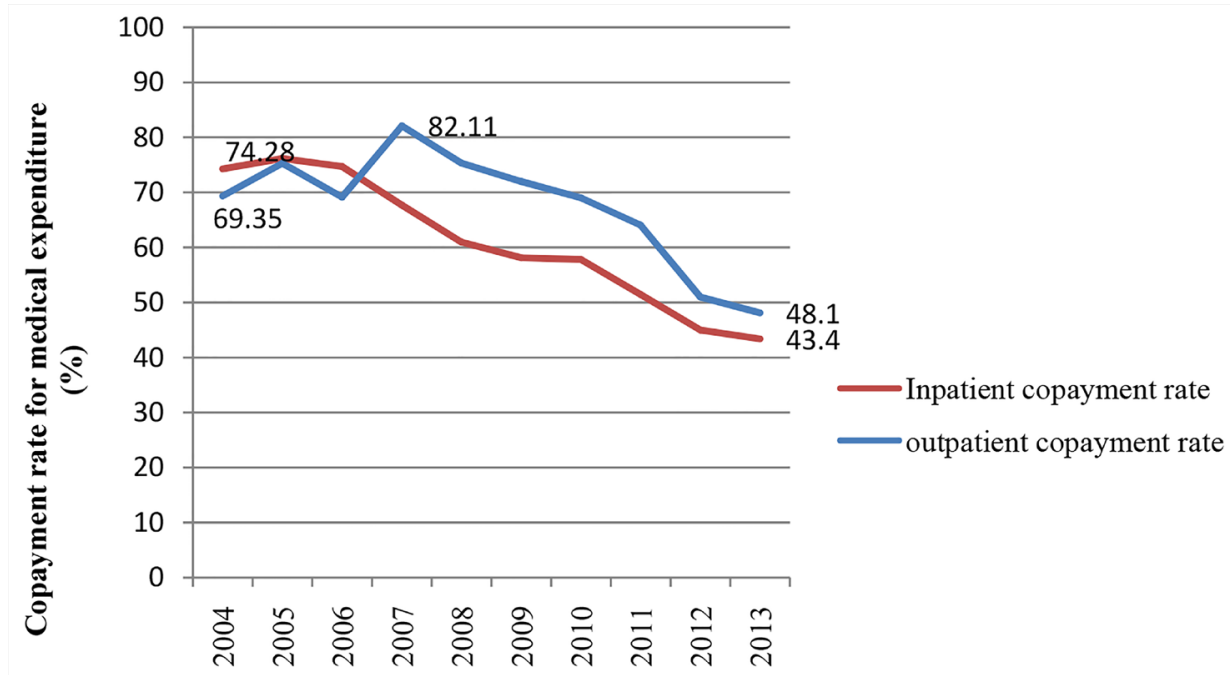

Figure 5. Farmer's copayment rate for medical expenditure from 2004 to 2013; Data source: National health financial statement yearbook from 2004 to 2014.

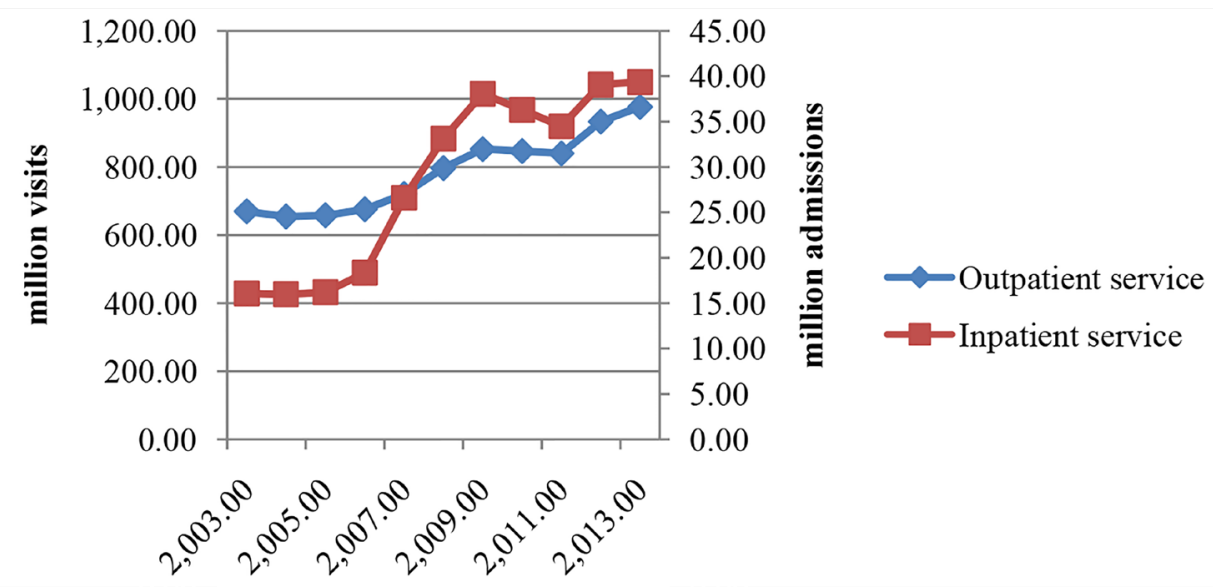

Figure 6. Volume of outpatient and inpatient services in township hospitals in rural China; Data source: National health statistics yearbook from 2004 to 2014. 
township health centers [47] [59]. Development of NCMS made strengthening and consolidating of the primary health system possible in rural China. It is a prime example of how to integrate health financing and health delivery systems.

\section{Challenges}

\subsection{Institutionalization and Legalization}

No act and regulations guaranteed the development of NCMS in China. China's Act on Social Insurance was enacted on 1st, July in 2010, but NCMS was not included in this act [65]. Regulation on New Rural Cooperative Medical Schemes, drafted by $\mathrm{MOH}$, was submitted to State Council in July 2010, but has seen no further legal movement therefore; NCMS remains operational without any legalization from the Chinese government.

\subsection{Cost Escalation, Payment Reform and Financial Protection}

Provider's payment reform is an important element necessary to perfect NCMS. Fee for service (FFS) was very popular in most providers in rural China when NCMS began, but FFS is not an optimal option to contain the growth of medical expenditure [66]. Given that NCMS could not finance sufficiently in the short run, provider's payment reform became one of the top priorities during the evolution of NCMS [65] [67] [68]. Payment reform such as case based payment, capitation and per diem were piloted in many counties in rural China during the last decade, but the breadth and width of payment reforms were very limited. Rapid growth of medical expenditure was not significantly contained when a limited scope payment reform was piloted. In patient expenditure for rural enrollees increased 13.9\% annually from 2008 to 2011. As a result, farmers' co-payment remained very high and the burden of disease they incurred was not significantly alleviated. In 2003, health spending per capita for rural residents (¥115.8) shared as $6 \%$ of household expenditure in rural areas, which was lower than that in urban residents [69]. In 2012, health spending per capita for rural residents increased to $¥ 513.8$, and share of household expenditure rose to $8.07 \%$ (Figure 7), which was higher than that for urban residents during the same term [70]. Studies also showed that NCMS provided some financial risk protection for individuals in rural China, moving rural residents from uninsured to underinsured, but it did not give them a solid safety net [45] [58] [71] [72].

\subsection{Solidarity and Equity}

Solidarity is an important principle needed to achieve universal health coverage [73]. Besides NCMS, urban employee basic medical insurance systems (UEBMI) which covered urban formal employees and urban resident basic medical insurance systems (URBMI) which covered informal employees or un-employees existed in urban China. There is a large difference in premium collection, benefit package and payment among different medical insurance systems in China. As shown in Table 3, in 2008, premium for urban employee basic medical insurance (UEBMI) was ten folds higher than premium 
for NCMS and urban resident basic medical insurance (URBMI); in 2011, the gap between NCMS, URBMI and UEBMI narrowed, but premium for UEBMI remained six times higher than that for the other two medical insurance systems. This was also the case for payment among three medical insurance systems between 2008 and 2011 in China. Due to different financing mechanisms and different benefit packages, reimbursement rates for medical expenditure for NCMS was significantly lower than that for UEBMI, as shown in Table 4, which is not an institutional arrangement of pro- solidarity. Un-solidarity among different medical insurance systems has become a barrier to achieve portability between NCMS and other medical insurance systems in China.

Equity is a commitment at the heart of UHC [74]. Equity has attracted an increasing amount of attention when measuring the effect of NCMS. Some studies suggested that

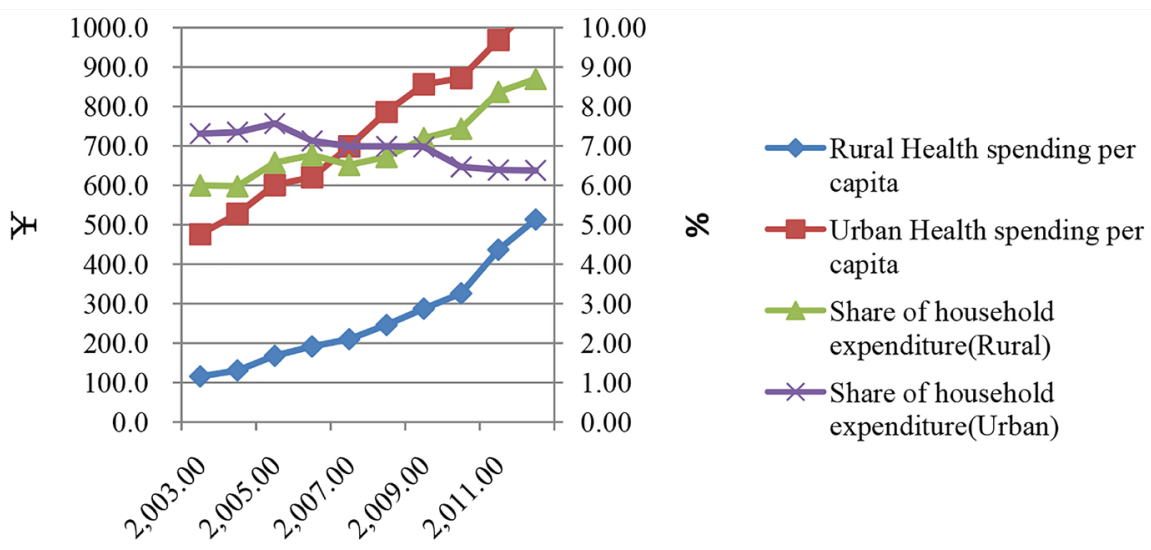

Figure 7. Rural and urban residents' health spending and its share of household expenditure from 2003 to 2012. Data source: Data source: China's statistical yearbook from 2004 to 2013.

Table 3. Premium and payment per capita among different medical insurance systems from 2008 to 2011 in China.

\begin{tabular}{ccccccc}
\hline & \multicolumn{3}{c}{ Premium per capita (¥) } & \multicolumn{3}{c}{ Payment per capita(¥) } \\
\cline { 2 - 6 } Year & NCMS & URBMI & UEBMI & NCMS & URBMI & UEBMI \\
\hline 2008 & 95.94 & 130.98 & 1443.07 & 81.25 & 54.03 & 1010.07 \\
2009 & 113.02 & 138.17 & 1673.81 & 110.78 & 91.87 & 1198.91 \\
2010 & 156.14 & 181.02 & 1666.51 & 142.15 & 136.47 & 1490.69 \\
2011 & 245.17 & 268.67 & 1772.80 & 205.64 & 186.79 & 1518.81 \\
\hline
\end{tabular}

Data source: China's statistical yearbook from 2009 to 2012.

Table 4. NCMS enrollees' reimbursement rate for medical expenditure in 2011.

\begin{tabular}{ccc}
\hline & Inpatient reimbursement rate (\%) & Outpatient reimbursement rate (\%) \\
\hline NCMS & 50.5 & 23.2 \\
URBMI & 49.9 & 29.7 \\
UEBMI & 68.3 & 50.1 \\
\hline
\end{tabular}

Data source: Mid review report on China's health reform progress (2011). 
NCMS reduced inequity of financing between the rich and the poor and public finance played an important role in contributing to more equitable health financing, and concluded that it was a pro-poor medical insurance design in terms of financing. While others suggested that NCMS did not reduced inequity of access to health services and even increased the gap between the poor and the rich and concluded that it was a prorich design in terms of access to health care services [45] [75] [76] [77] [78].

\subsection{Portability and Sustainability}

Portability was not achieved creating the emergence of double coverage. Many provinces tried to solve portability through on point reimbursement when rural residents used health services outside of registered counties but portability among provinces remains a problem. Transferability for rural residents among NCMS, UEBMI and URBMI has still not been achieved. No information system or portal existed to identify double covered. As NCMS adhered with voluntary enrolling on a household basis, many farmers who moved to urban areas would be double covered when they were insured by UEBMI or URBMI. In 2010, URBMI covered 194.72 million enrollees, $9 \%$ of them were rural residents [79] double covered by NCMS and URBMI. Double coverage requires double premium payments, but farmers could only receive reimbursement once either from NCMS or URBMI. The achievement of portability among different medical insurance systems will prevent the issue of double coverage.

Premium for NCMS is insufficient compared to UEBMI and URBMI. NCMS remains a voluntary enrolled medical insurance scheme, and financing for NCMS is not institutionally guaranteed or legalized. Responsibilities for NCMS contributions between individuals and public finance, and between central government and local governments have not been identified. Enrollees' contribution to NCMS fund is very low compared to UEBMI [80] [81]. No institutional arrangement exists for stably increasing NCMS premium and premium increasing still depends on fiscal space and political commitment [82].

Population aging in rural China exacerbated insufficient financing for NCMS. Three decades of the one child policy quickly created an aging society in China. [83] Rapid urbanization accelerated an aging population in rural China, due to many youth and young adults moving into urban areas. The percentage of aging population in rural area was $15.4 \%$ in 2011, which was higher than that in urban areas in China [84]. In some counties, aging enrollees (older than 60 years) occupied more than $35 \%$ of NCMS enrollees [85]. Rapid demographic transition has led to a notable shift in the burden of illness, currently dominated by an epidemic of chronic, non-communicable diseases (NCDs) [86] [87]. Increased aging made it difficult to increase premiums for NCMS, and therefore it was unfavorable to establish a sustainable and increasing financing mechanism in rural China.

\section{Policy Implications}

Universal health coverage is not an intrinsic characteristic of developed countries. Low 
and middle-income countries (LMICs) and transitional economies can also build their medical insurance systems based on country context and move towards universal health coverage [88] [89] [90].

Political commitment is a premise to achieve universal health coverage. China is the largest developing country in the world, and more than 800 million residents live in rural areas. It is a big challenge for China's government to build a health safety net for such a huge rural population; China's government made a promise ten years ago and successfully kept their promise.

Public finance is of critical importance to cover informal employees, especially for rural residents. Enrolling informal employees is a big challenge to move toward universal health coverage in developing countries, especially in large countries such as China. During the period of establishing NCMS, the contribution of China's public finance played a leading role. It is very impressive that China successfully built and implemented NCMS in only ten years.

Health financing should develop in line with health delivery system. China's government integrated health financing and primary health delivery systems successfully during the development of NCMS, which provided more equitable access to primary health care to rural residents than ever before. The financing level of NCMS is relatively low, especially in the years when it was just built. Given the limited fund, to cover more people and more service the Chinese government made much effort to strengthen the primary health system and incentive people to use the primary health service. After several years, both the NCMS and primary health system got developed.

Portability, an important element of UHC, should be considered when designing health insurance systems. Portability was neglected when NCMS initiated in 2003 in China. Non-portability limited the function of NCMS and was unhelpful in improving the benefits of enrollees. With the urbanization in China, more and more rural people went to big cities to work; however, they were usually informal employees and didn't enroll in the urban employee health insurance, which cover the formal employees in urban. When these informal employees get sick, they have to go back to their hometown to get treatment and reimbursement. China is still working towards a national NCMS platform to create portability.

Solidarity and equity should be adhered when designing health insurance systems. China is experiencing rapid socioeconomic transition, creating a large public concern of how to narrow the socioeconomic gap among different communities [82]. As a component of social security, NCMS should be helpful in narrowing the benefit gap and improve the equity of health financing between urban and rural residents. China is trying to improve equity of health financing through subsidizing vulnerable populations but solidarity between urban and rural areas remains a problem.

UHC will be achieved over a long period, but developing countries can accelerate their progress if they can learn from experiences and lessons of other countries. Most developed countries spent more than 20 years achieving UHC creating many experiences and lessons [91] [92]. With rapid development of NCMS, China successfully 
crossed the period from uninsured to under insured and is on track to transition from underinsured to UHC. The evolution of NCMS indicates that developing countries can reduce time achieving UHC when learning from the experiences towards UHC of other countries.

\section{Acknowledgements}

Special gratitude is given to Prof. Shenglan TANG (Duke University) for his valuable discussions and advices during the stage of paper-writing, and Betsy Asma (Duke University) for editing the manuscript.

\section{References}

[1] Liu, Y., Rao, K. and Hu, S. (2002) Study on the Necessity of Building Health Security System in Rural China and Related Policy Issues. Asian Development Bank.

[2] Feng, X., Tang, S., Bloom, G., Segall, M. and Gu, X. (1995) Cooperative Medical Schemes in Contemporary Rural China. Social Science \& Medicine, 41, 1111-1118. http://dx.doi.org/10.1016/0277-9536(94)00417-R

[3] Zhu, A.R., Wu, Y.M. and Ye, Y.D. (1991) Reestablish Cooperative Health Care. Chinese Rural Health Service Administration, 12, 19. (In Chinese)

[4] Blumenthal, D. and Hsiao, W. (2005) Privatization and Its Discontents-The Evolving Chinese Health Care System. The New England Journal of Medicine, 353, 1165-1170. http://dx.doi.org/10.1056/NEJMhpr051133

[5] Liu, Y., Hsiao, W., Li, Q., Liu, X. and Ren, M. (1995) Transformation of China's Health Care Financing. Social Science \& Medicine, 41, 1085-1093. http://dx.doi.org/10.1016/0277-9536(95)00428-A

[6] Hsiao, W. (1984) Transformation of Health Care in China. The New England Journal of Medicine, 310, 932-936. http://dx.doi.org/10.1056/NEJM198404053101428

[7] Gu, X., Bloom, G., Tang, S., Zhu, Y., Zhou, S. and Chen, X. (1993) Financing Health Care in Rural China: Preliminary Report of a Nationwide Study. Social Science \& Medicine, 36, 385-391. http://dx.doi.org/10.1016/0277-9536(93)90400-X

[8] Chen, X.M., Hu, D.W. and Lin, Z.H. (1993) The Rise and Decline of the Cooperative Medical System in Rural China. International Journal of Health Services, 23, 731-742. http://dx.doi.org/10.2190/F8PB-HGJH-FHA8-6KH9

[9] Carrin, G., Ron, A., Yang, H., Wang, H., Zhang, T.H., Zhang, L.C., et al. (1999) The Reform of the Rural Cooperative Medical System in the People's Republic of China: Interim Experience in 14 Pilot Counties. Social Science \& Medicine, 48, 961-972. http://dx.doi.org/10.1016/S0277-9536(98)00396-7

[10] Tang, S. (1997) The Changing Role of the Township Health Centers in the Context of Economic Reform in China. IDS Bulletin, 28, 39-47.

[11] Jackson, S., Sleigh, A.C., Li, P. and Liu, X. (2005) Health Finance in Rural Henan: Low Premium Insurance Compared to the Out-of-Pocket System. The China Quarterly, 181, 137-157. http://dx.doi.org/10.1017/S0305741005000081

[12] Liu, K. and Fan, W. (2002) The Analysis on Fluctuation of Cooperative Medical Scheme of Two Counties in Shanxi Province in 1990's. Chinese Health Economics, 21, 14-17. (In Chinese)

[13] The World Bank (1997) Financing Health Care: Issues and Options for China. 
[14] Center for National Health Statistical Information (PRC) (1994) Research on National Health Services: Analysis Report of the First National Health Service Survey in 1993. Beijing. (In Chinese)

[15] Center for National Health Statistical Information (PRC) (1999) Research on National Health Services: Analysis Report of the Second National Health Service Survey in 1998. Beijing. (In Chinese)

[16] Gustafsson, B. and Li, S. (2003) Expenditures on Education and Health Care and Poverty in Rural China. China Economic Review, 15, 292-301. http://dx.doi.org/10.1016/j.chieco.2003.07.004

[17] Liu, Y., Rao, K. and Hsiao, W. (2003) Medical Expenditure and Rural Impoverishment in China. Journal of Health Population Nutrition, 21, 216-222.

[18] You, X. and Kobayashi, Y. (2009) The New Cooperative Medical Scheme in China. Health Policy, 91, 1-9. http://dx.doi.org/10.1016/j.healthpol.2008.11.012

[19] WHO (2000) The World Health Report 2000-Health Systems: Improving Performance. Geneva.

[20] Lu, H. and Fang, Q. (2004) The Cause and Countermeasure about the Difficulty of Chinese Rural Inhabitants in Their Seeking Medical Service. Public Health and Preventive Medicine, 2, 7-9. (In Chinese)

[21] Yu, D. (2006) Perfecting the Medical Security System: The Fundamental Solution to the Issue of Inadequate and Overly Expensive Medical Services. Chinese Journal of Hospital Administration, 2, 73-76. (In Chinese)

[22] CPC Central Committee and State Council (2002) Decision to Further Strengthen Health Work in Rural Areas. (In Chinese)

[23] Ministry of Health, Ministry of Finance, and Ministry of Agriculture (2003) Directives on the Establishment of New Rural Cooperative Medical System. (In Chinese)

[24] McKee, M., Tangcharoensathien, V., David, B., et al. (2011) Independent Review of the Health Reforms of the People's Republic of China: Helping to Achieve a Sustainable and Equitable Health System.

[25] Charles, W. and Lu, X. (2011) Implementing Health Care Reform Policies in China: Challenges and Opportunities. Center for Strategic and International Studies.

[26] WHO (2010) The World health Report 2010-Health Systems Financing: The Path to Universal Coverage. Geneva.

[27] Department of Regulation, Planning and Finance, Ministry of Health (PRC). National Health Financial Statement 2003. (In Chinese)

[28] Department of Rural Health, Research Center for Rural Cooperative Medical Schemes, Ministry of Health (PRC). National Handbook of New Rural Cooperative Medical Scheme Information 2003-2004. (In Chinese)

[29] Department of Rural Health, Research Center for Rural Cooperative Medical Schemes, Ministry of Health (PRC). National Handbook of New Rural Cooperative Medical Scheme Information 2005. (In Chinese)

[30] Department of Rural Health, Research Center for Rural Cooperative Medical Schemes, Ministry of Health (PRC). National Handbook of New Rural Cooperative Medical Scheme Information 2006. (In Chinese)

[31] MOH, NDRC, MOF, MOA, SFDA, SATCM (2006) Notice on Advancing NCMS. (In Chinese)

[32] Wu, Y. (2007) Advancing NCMS around the Country and Keeping Sustainable Development. Xinhua News Agency. 
[33] Department of Rural Health, Research Center for Rural Cooperative Medical Schemes, Ministry of Health (PRC). National Handbook of New Rural Cooperative Medical Scheme Information 2007. (In Chinese)

[34] Department of Rural Health, Research Center for Rural Cooperative Medical Schemes, Ministry of Health (PRC). National Handbook of New Rural Cooperative Medical Scheme Information 2008. (In Chinese)

[35] CPC Central Committee and the State Council (2009) Opinions on Deepening the Health Care System Reform. (In Chinese)

[36] MOH, Ministry of Civil Affair, MOF, MOA, SATCM (2009) Opinion on Fixing and Developing NCMS. (In Chinese)

[37] Zhang, C., Yang, H. and Ye, Y. (1998) General Technical Report Chinese Rural Cooperative Medical Scheme Study. Chinese Rural Health Service Administration, 4, 11-20. (In Chinese)

[38] Mao, Z. (2001) Review of and Reflection on the Experiment of Cooperative Medical Care in Distressed Rural Areas. Chinese Journal of Hospital Administration, 9, 550-552. (In Chinese)

[39] Wang, Y. (2008) Some Lessons from 30-Year Development of Rural Cooperative Medical System. Chinese Journal of Health Policy, 11, 21-26. (In Chinese)

[40] National Evaluation Group for New Rural Cooperative Medical Schemes (2006) Evaluation Report on New Rural Cooperative Medical Scheme Pilot Policy in China. (In Chinese)

[41] Deng, B. (2005) Operation, Issues and Countermeasures for New Rural Cooperative Medical Schemes. Jiangxi Social Science, 2, 249-252. (In Chinese)

[42] MOH, MOF (PRC) (2008) Notice on Implementing New Rural Cooperative Medical Scheme. (In Chinese)

[43] MOH, Ministry of Civil Affair (PRC) (2010) Opinion on Improving Medical Security for Children's Major Diseases in Rural China. (In Chinese)

[44] MOH, Ministry of Human Resource and Social Security, Ministry of Civil Affair, MOF, and China Disabled Person's Federation (PRC) (2010) Notice on Including Some Medical Rehabilitation Services into Benefit Packages of Basic Medical Securities. (In Chinese)

[45] Wagstaff, A., Lindelow, M., Gao, J., Xu, L. and Qian, J.C. (2009) Extending Health Insurance to the Rural Population: An Impact Evaluation of China's New Cooperative Medical Scheme. Journal of Health Economics, 28, 1-19. http://dx.doi.org/10.1016/j.jhealeco.2008.10.007

[46] Dai, B.Z., Zhou, J.Z., Mei, Y.J., Wu, B. and Mao, Z.F. (2011) Can the New Cooperative Medical Scheme Promote Rural Elders' Access to Health-Care Services? Geriatrics \& Gerontology International, 11, 239-245. http://dx.doi.org/10.1111/j.1447-0594.2011.00702.x

[47] Lei, X.Y. and Lin, W.C. (2009) The New Cooperative Medical Scheme in Rural China: Does More Coverage Mean More Service and Better Health? Health Economics, 18, S25-S46. http://dx.doi.org/10.1002/hec.1501

[48] Center for National Health Statistical Information (PRC) (2011) Mid Review Report on China's Health Reform Progress. (In Chinese)

[49] Center for National Health Statistical Information (PRC) (2004) Research on National Health Services: Analysis Report of the Third National Health Service Survey in 2003. Beijing. (In Chinese)

[50] Center for National Health Statistical Information (PRC) (2016) Research on National Health Services: Analysis Report of the Third National Health Service Survey in 2013. Beijing. (In Chinese) 
[51] Center for National Health Statistical Information (PRC) (2009) Research on National Health Services: Analysis Report of the Fourth National Health Service Survey in 2008. Beijing. (In Chinese)

[52] Cheng, B., Wang, Z. and Yang, Z. (2008) The Effect of NCMS on Improving Maternal Health Deliveries. Chinese Maternal and Child Health, 10, 1323-1324. (In Chinese)

[53] Tang, J. and Li, N. (2008) Use of Maternal Health Care Services in Po or Regions in Sichuan. Journal of Sichuan University (Medical Science Edition), 6, 1004-1006. (In Chinese)

[54] MOH (PRC) (2004) National Health Statistics Yearbook 2004. Beijing. (In Chinese)

[55] MOH (PRC) (2012) National Health Statistics Yearbook 2012. Beijing. (In Chinese)

[56] Zhang, N. and Zhang, C. (2011) An Empirical Analysis of Influencing Factors on Farmers Health Status. Chinese Primary Health Care, 11, 6-7.

[57] Fan, T., Cao, Q., Jiang, L. and Xu, Z. (2011) Effects of New Rural Cooperative Medical Scheme on Self-Perceived Health of Rural Residents. Journal of Shanghai Jiaotong University (Medical Science), 12, 1763-1766.

[58] General Office, MOH (PRC) (2011) Notice on Establishing National Platform for New Rural Cooperative Medical Scheme. (In Chinese)

[59] Yip, W. and Hsiao, W.C. (2009) Non-Evidence-Based Policy: How Effective Is China's New Cooperative Medical Scheme in Reducing Medical Impoverishment? Social Science \& Medicine, 68, 201-209. http://dx.doi.org/10.1016/j.socscimed.2008.09.066

[60] Babiarz, K.S., Miller, G., Yi, H.M., Zhang, L.X. and Rozelle, S. (2012) China's New Cooperative Medical Scheme Improved Finances of Township Health Centers but Not the Number of Patients Served. Health Affairs, 31, 1065-1074.

[61] Chen, J. and Lin, Z. (2009) A Study on Linking Rural Medical Assistance with New Rural Cooperative Medical System in China. Chinese Journal of Health Policy, 2, 6-10. (In Chinese)

[62] Liu, J. (2009) The Third Wave of Informationization of Medical Insurance. China Hospital $C E O$, 5, 83-85. (In Chinese)

[63] One Third of Township Hospitals Are on the Verge of Collapse. (In Chinese) http://news.sina.com.cn/c/2003-11-28/07031204267s.shtml

[64] New Rural Cooperative Medical Scheme Save Township Hospitals. (In Chinese) http://news.sina.com.cn/c/2007-03-13/001712498090.shtml

[65] People's Republic of China Social Insurance Act. (In Chinese) http://www.china.com.cn/policy/txt/2010-10/29/content 21225907.htm

[66] Meng, Q.Y., Yip, W. and Langenbrunner, J. (2010) Health Provider Payment Reforms in China: What International Experience Tells Us.

[67] Hu, S.L., Tang, S.L., Liu, Y.L., et al. (2008) Reform of How Health Care Is Paid for in China: Challenges and Opportunities. The Lancet, 372, 1846-1853.

http://dx.doi.org/10.1016/S0140-6736(08)61368-9

[68] Yip, W.C.-M., Hsiao, W., Meng, Q.Y., Chen, W. and Sun, X.M. (2010) Realignment of Incentives for Health-Care Providers in China. The Lancet, 375, 1120-1130. http://dx.doi.org/10.1016/S0140-6736(10)60063-3

[69] National Bureau of Statistics of China (2004) China Statistical Yearbook 2004. (In Chinese)

[70] National Bureau of Statistics of China (2012) China Statistical Yearbook 2012. (In Chinese)

[71] Babiarz, K.S., Miller, G., Yi, H.M., Zhang, L.X. and Rozelle, S. (2010) New Evidence on the Impact of China's New Rural Cooperative Medical Scheme and Its Implications for Rural Primary Healthcare: Multivariate Difference-in-Difference Analysis. BMJ, 341, c5617. http://dx.doi.org/10.1136/bmj.c5617 
[72] Tang, S.L., Tao, J.J. and Bekedam, H. (2012) Controlling Cost Escalation of Healthcare: Making Universal Health Coverage Sustainable in China. BMC Public Health, 12, S8. http://dx.doi.org/10.1186/1471-2458-12-S1-S8

[73] Kornai, J. and Eggleston, K. (2001) Welfare, Choice, and Solidarity in Transition: Reforming the Health Section in Eastern Europe.

[74] World Health Organization and the World Bank Group (2013) Monitoring Progress towards Universal Health Coverage at Country and Global Levels: A Framework.

[75] Zhou, Z.L., Gao, J.M., Fox, A., Rao, K., Xu, K., Xu, L. and Zhang, Y.G. (2011) Measuring the Equity of Inpatient Utilization in Chinese Rural areas. BMC Health Services Research, 11, 201. http://dx.doi.org/10.1186/1472-6963-11-201

[76] Yang, W. (2013) China's New Cooperative Medical Scheme and Equity in Access to Health Care: Evidence from a Longitudinal Household Survey. International Journal for Equity in Health, 12, 20. http://dx.doi.org/10.1186/1475-9276-12-20

[77] Yuan, S.S., Rehnberg, C., Sun, X.J., Liu, X.Y. and Meng, Q.Y. (2014) Income Related Inequalities in New Cooperative Medical Scheme: A Five-Year Empirical Study of Junan County in China. International Journal for Equity in Health, 13, 38. http://dx.doi.org/10.1186/1475-9276-13-38

[78] Liang, X., Guo, H., Jin, C., Peng, X. and Zhang, X. (2012) The Effect of New Cooperative Medical Scheme on Health Outcomes and Alleviating Catastrophic Health Expenditure in China: A Systematic Review. PLoS ONE, 7, e40850. http://dx.doi.org/10.1371/journal.pone.0040850

[79] National Evaluation Expert Panel for Urban Residents' Medical Insurance System (2011) Evaluation Report for Urban Residents' Medical Insurance System 2010. (In Chinese)

[80] Liu, G.G., Ikegami, N. and Langenbrunner, J. (2010) The Path to Integrated Insurance Systems in China.

[81] Liang, L.L. and Langenbrunner, J.C. (2013) The Long March to Universal Coverage: Lessons from China.

[82] Dai, T. (2012) Report on China's Health Care Reform Evaluation Study. (In Chinese)

[83] Lim, E. and Spence, M. (2010) Thoughts and Suggestions for China's 12th Five-Year-Plan from an International Perspective.

[84] Chen, H. (2012) Research on Demand and Utilization of Health Service among the Elderly in Rural Areas under the Background of Aging. Peking Union Medical College. (In Chinese)

[85] Zhu, K. and Zhang, X. (2013) Comparative Analysis of the Operative Effect of Basic Medical Insurance for Urban and Rural Citizens under Different Governance. Chinese Journal of Health Policy, 2, 8-13. (In Chinese)

[86] Xu, Y., Wang, L.M., He, J., et al. (2013) Prevalence and Control of Diabetes in Chinese Adults. JAMA, 310, 948-959. http://dx.doi.org/10.1001/jama.2013.168118

[87] Tang, S.L., Ehiri, J. and Long, Q. (2013) China's Biggest, Most Neglected Health Challenge: Non-Communicable Diseases. Infectious Diseases of Poverty, 2, 7. http://dx.doi.org/10.1186/2049-9957-2-7

[88] Lagomarsino, G., Garabrant, A., Adyas, A., Muga, R. and Otoo, N. (2012) Moving towards Universal Health Coverage: Health Insurance Reforms in Nine Developing Countries in Africa and Asia. The Lance, 380, 933-943. http://dx.doi.org/10.1016/S0140-6736(12)61147-7

[89] Sachs, J.D. (2012) Achieving Universal Health Coverage in Low-Income Settings. The Lancet, 380, 944-947. http://dx.doi.org/10.1016/S0140-6736(12)61149-0 
[90] Fan, V.Y. and Savedoff, W.D. (2012) The Health Financing Transition: A Conceptual Framework and Empirical Evidence. Result for Development Institute Working Paper.

[91] Savedoff, W.D., de Ferranti, D., Smith, A.L. and Fan, V. (2012) Political and Economic Aspects of the Transition to Universal Health Coverage. The Lancet, 380, 924-932.

http://dx.doi.org/10.1016/S0140-6736(12)61083-6

[92] Giedion, U., Alfonso, E.A. and Díaz, Y. The Impact of Universal Coverage Schemes in the Developing World: A Review of the Existing Evidence. The World Bank Working Paper.

Submit or recommend next manuscript to SCIRP and we will provide best service for you:

Accepting pre-submission inquiries through Email, Facebook, LinkedIn, Twitter, etc. A wide selection of journals (inclusive of 9 subjects, more than 200 journals)

Providing 24-hour high-quality service

User-friendly online submission system

Fair and swift peer-review system

Efficient typesetting and proofreading procedure

Display of the result of downloads and visits, as well as the number of cited articles

Maximum dissemination of your research work

Submit your manuscript at: http://papersubmission.scirp.org/

Or contact me@scirp.org 